\title{
Evolution of posterior cervical and occipitocervical fusion and instrumentation
}

\author{
John R. Vender, M.D., Andy J. Rekito, M.S., Steven J. Harrison, M.S., \\ AND DENNIS E. MCDONNELL, M.D. \\ Department of Neurosurgery and Medical Illustration Graduate Program, Medical College of \\ Georgia; and Department of Neurosurgery, Gunderson-Lutheran Clinic, La Crosse, Wisconsin
}

\begin{abstract}
The past several decades have been the setting for a remarkable evolution of spinal instrumentation technology. The advancements that have been made have allowed previously complex disorders of the cervical spine, the atlantoaxial articulation, and the occipitocervical junction to be managed more effectively with direct methods of internal fixation and arthrodesis. This has resulted in improvements in patient outcomes and fusion success rates. The improved strength of instrumentation constructs allows minimal, if any, external bracing, obviating the need for a halo orthosis in many cases. In this paper the authors review key events that have occurred in neuroimaging, biomechanical testing, and the development of fusion and instrumentation constructs.
\end{abstract}

\section{KEY WORDS • posterior approach • cervical spine • occipitocervical junction • atlantoaxial articulation $\bullet$ arthrodesis $\bullet$ instrumentation $\bullet$ history of surgery}

The cervical spine presents a challenge to the spinal surgeon because of its limited biomechanical strength, the paucity of some osseous structural elements, the neural and vascular structures contained within the spine, and the frequent variation in anatomy among patients. Any instrumentation construct must be strong enough to resist force in multiple axes of motion, yet delicate enough to integrate into the cervical spinal elements. In addition, a complex spinal transition zone occurs at the occipitocervical junction. Successful attainment of arthrodesis in this transition zone has been a challenge for many years.

Numerous pathological conditions can destabilize the occipitocervical junction, atlantoaxial articulation, and subaxial cervical spine. Common mechanisms of instability include but are by no means limited to trauma, rheumatoid arthritis, inflammatory or infectious lesions, neoplasms, and congenital deformity. Common to all these processes is the resulting neural compression and/or craniospinal or spinal instability. The rapid identification of the pathological process and the subsequent correction of subluxation or malalignment, decompression, and, ultimately, stabilization must be undertaken. Every patient presents a unique diagnostic and therapeutic challenge.

\footnotetext{
Abbreviations used in this paper: $\mathrm{CSF}=$ cerebrospinal fluid; $\mathrm{CT}=$ computerized tomography; $\mathrm{MR}=$ magnetic resonance; $\mathrm{VA}=$ vertebral artery; $\mathrm{VB}=$ vertebral body; $3 \mathrm{D}=$ three-dimensional.
}

Although in this manuscript we will focus on posterior approaches for arthrodesis and instrumentation of the craniocervical junction, atlantoaxial articulation, and subaxial cervical spine, it is important to realize that posterior approaches are not always the correct solution. Many cervical spinal lesions, as well as the majority of occipitocervical, lesions, are anterior and anterolateral in orientation. Previous attempts at direct posterior approaches for these lesions have been abandoned in favor of anterior and anterolateral approaches that have proved to be more direct and effective, and associated with lower risks of morbidity. Posterior surgical decompression remains a vital component in the management of these anteriorly or anterolaterally situated lesions in some select cases. Also, it is not necessary in every case to perform an arthrodesis of the occipitocervical articulation or the cervical spine. Careful preoperative decision making requires assessments of the functional stability of the spine, anterior instrumentation and fusion options, and the need for posterior supplementation. In cases of posteriorly situated lesions in which posterior surgical decompressive approaches are appropriate, an additional assessment of the stability of the spine must be made. In cases in which the pathological process or the surgical approach to correct this process results in the instability of the spine, posterior cervical arthrodesis is appropriate. In some rare cases a combined anterior-posterior supplementation is required. 
Much of the evolution of posterior spinal instrumentation technology is attributable to advances in neuroimaging; an improved understanding of the biomechanical and anatomical relationships between the structures involved; and an enhanced materials science technology from which smaller, lower profile (yet stronger), instrumentation constructs, which are suitable for the unique demands of the cervical spinal region, have been produced. In addition, many constructs have now been designed to be compatible with MR imaging, a key imaging modality used in the evaluation of additional progression of many of the lesions being treated.

\section{METHODS OF INVESTIGATION}

A retrospective literature review was performed to evaluate key contributions in the evolution of occipitocervical, atlantoaxial, and posterior subaxial cervical spinal instrumentation systems. We realize that by no means is this a comprehensive list of all contributions of the various investigators and spinal surgeons who have worked in this area. Nevertheless, we have attempted to identify and illustrate key procedures in the context of contributions associated with these procedures in the advancement of spinal surgery. Due to the unique characteristics of the various regions involved in the cervical spine, our discussion will be divided into "zones," which include the occipitocervical articulation, the atlantoaxial articulation, and the subaxial cervical spine. Each of these regions has unique anatomical and biomechanical features that require slightly different strategies for successful arthrodesis.

\section{NEUROIMAGING METHODS}

\section{Overview}

It is without question that the successful identification of the pathological lesions affecting the occipitocervical junction and the cervical spine would be impossible without advances made within the relatively new field of neuroradiology. In addition, the ability to view the osseous, neural, vascular, and ligamentous structures of the spine and the craniospinal junction three-dimensionally has greatly enhanced our understanding of the biomechanical and structural issues of this region. By accurately determining the orientation of pathological lesions to the various structures in the region it is possible to make complex surgical decisions involving operative approaches, assessments of stability, and determinations about the optimal method of instrumentation and arthrodesis in cases in which instability either exists or will exist.

\section{Lumbar Puncture, Radiography, and Myelography}

Corning first described lumbar puncture in $1855 .{ }^{59}$ Subsequently, Queckenestedt observed that bilateral jugular venous compression would increase CSF pressure. He further observed that this phenomenon could be blocked with obstruction of CSF pathways. This observation indicated the presence of an intraspinal lesion, but no imaging modality existed to supplement the clinical neurological examination in localizing or visualizing the lesion, until the development of the radiograph in 1891 by Roentgen.
At this time osseous structures and abnormalities, calcified lesions, and soft-tissue shadows could be visualized for the first time. The concept of myelography was subsequently developed by Dandy, ${ }^{13}$ who in 1919 described an injection of intraspinal air for the diagnosis of intracranial lesions. ${ }^{59}$ In his manuscript Dandy also surmised that air myelography would aid in the localization of spinal tumors. Sicard, in 1921, described a myelography study in which an iodized oil (Lipiodol) that is radiopaque was used. ${ }^{60}$ Air was ultimately replaced by iodinated contrast agents including pantopaque and metrizamide. ${ }^{59,76}$ Spine radiology was further enhanced by the development of $\mathrm{x}-$ ray tomography. This imaging modality provided more precise identification of osseous structures in the spine, particularly the craniocervical junction. The next critical development occurred in the late 1960s, when Hounsfield developed a method by which, using x-ray data, 3D structures could be identified as such within a 3D space. When these images were reconstructed, a CT image was created producing the first CT scan of the brain in $1971 .{ }^{60}$ Unlike many previous technological innovations, CT scanning was rapidly and widely accepted. Shortly after the development of CT scanning, MR imaging emerged as an additional imaging modality for the nervous system. Magnetic resonance imaging was based on work initially performed by Bloch and Purcell in $1946 .{ }^{60}$ Further developments in MR imaging led to more rapid acquisition of data and improved image resolution. With CT and MR imaging, $3 \mathrm{D}$ evaluation of the cervical spine and the craniocervical junction was possible. Lesions were easily identified and localized. Decisions regarding spinal stability were possible. Computerized tomography scanning after myelography enabled additional delineation of compression in lesions involving the neuraxis. The dynamic assessment of the spine, such as flexion-extension myelography or MR imaging, further delineated areas of instability and compression. Three-dimensional stereotactic workstations that contain CT and MR imaging data allow for surgical planning in preparation for instrumentation selection and implantation. The ongoing, current evolution in the capabilities of intraoperative CT and MR imaging will further enable a surgeon to localize structures accurately during treatment of the pathological process and during placement of instrumentation in optimal locations so as to maximize the chances of successful arthrodesis with minimal risk to the surrounding structures.

\section{OCCIPITOCERVICAL FUSION}

\section{Overview}

The occipitocervical junction, which comprises the occiput, atlas, and axis, represents a unique and complex interface between the cranium and the rostral cervical spine. More than $50 \%$ of the rotation and flexion-extension of the head and neck occurs in that region. In addition, the osseous articulations and their ligamentous support structures must resist force in eight axes of rotation. These include flexion, extension, bilateral lateral bending; and bilateral rotation, distraction, and axial loading. Instrumentation constructs not only must resist forces in all of these vectors, but also must resist the significant lever arm created by the suboccipital bone and the cervical spine, 
which meet at a $50^{\circ}$ angle. Any instrumentation construct designed for use in this region must, therefore, have adequate dimensions to interface with the osseous structures of the spinal structures as well as have sufficient rigidity and purchase to resist these forces until bone fusion can occur. Great flexibility must be afforded to allow for the multiple anatomical variations seen in this region. ${ }^{80}$

In the early 1900s occipitocervical instability and lesions located at the occipitocervical junction were considered inoperable and terminal. Since the first description of an occipitocervical fusion by Forrester in 1927, multiple methods of fusion in this region have been described. Descriptions of simple onlay bone grafts with halo immobilization; wire, pin, or hook constructs; rigid metallic loops and rectangles fixed to the bone with either screws or wires; and most recently, plate or rod constructs with screws have all been described. In general the evolution of this technology has focused on providing increasingly more rigid constructs to facilitate bone fusion and to minimize the need for and duration of external immobilization.

\section{Onlay Bone Graft With or Without Wiring}

Stand-alone onlay bone graft techniques have the advantage of being simple and straightforward. There is no morbidity associated with instrumentation. In a recent series, a fusion rate of $89 \%$ was reported; however, stability is not immediately conferred on the segment. Patients require prolonged immobilization in tongs, Minerva jackets, or a halo orthosis until successful arthrodesis occurs. This typically takes at least 12 weeks. ${ }^{20}$ The addition of wires to stabilize the segments posteriorly and secure the bone graft has enhanced immediate stability in some planes of motion.

Foerster, ${ }^{24}$ in 1927 and Juvara and Dimitriu in $1928^{40}$ attempted to fuse progressive atlantoaxial dislocations by using fibular and tibial grafts, respectively. Kahn and Yglesias ${ }^{41}$ were the first to report the use of an iliac crest autograft in 1935 to stabilize the spine in a patient with atlantoaxial subluxation after conservative therapy for a fracture of the dens had failed. Rand ${ }^{61}$ reported the use of this procedure in cases of spontaneous atlantoaxial subluxation in 1944.

In 1967 Hamblen $^{32}$ described his experience in the use of an onlay bone graft with or without occipital wiring, which was based on a method originally described by Cone and Turner ${ }^{9}$ in 1937. In the Hamblen series he treated nine patients with a single iliac crest graft that extended from the occiput to levels ranging in the axis through C-6; two patients received two iliac grafts that extended from the occiput to C3-4 in one case and to C3-4 and $\mathrm{C}-5$ in the second case. Two patients received tibial grafts: one received two grafts extending from the occiput to the C5-6 laminae and the second patient received a single graft extending from the occiput to the spine of the axis. The method, which the authors credited to the London Hospital and Mr. H. Osmond-Clarke and Mr. D. W. C. L. Northfield, involved a standard midline incision extending from above the occipital external protuberance to the level of C-5 or C-6. The spinous processes, laminae, and undersurface of the occiput were then prepared by abrading the bone with the aid of either a dental drill, in the case of the occiput, or a fine nibbling forceps, in the case of the laminae. Burr holes were created on each side of the foramen magnum 0.5 inches from the midline. The size and style of the burr hole varied according to the type of graft that was used. In cases in which tibial grafts were used, the outer table alone was removed. This allowed for the impaction of the superior ends of the tibial grafts. Fullthickness holes were created so that wires could be passed to ultimately fix the superior end of the iliac crest onlay grafts. Wires were passed from one hole to the other after the dura mater had been carefully dissected free from the inner table of the skull. This technique was preferred over passage of the wires from the drill holes through the foramen magnum due to adherence of the dura and periosteum to the bone at the margin of the foramen magnum. In cases of iliac crest grafts, a single cortical surface and a thick cancellous portion of bone were harvested. The curvature of the iliac crest graft conformed to the spine. When two grafts were used, the single harvested graft was split before the holes were drilled to retain the wires. The inferior portion of the graft was secured to the spine with wires that had passed below the lamina. These were chosen in preference to the spinous process, which gave less secure attachment. These wires were then threaded also through holes in the graft and then tightened. In cases in which there was anterior translation of the atlas, this was secured to the graft and, by means of wire tightening, was reduced to a more anatomical position. Twenty-two-gauge standard braided stainless steel wire was used. In cases in which twin tibial grafts were used, they were impacted into the diploë, which was exposed by removal of the outer table while the lower ends were again wired to either the laminae or the base of the spinous process. In cases in which excessive instability was present before surgery, skull traction was maintained for several weeks postoperatively. Patients were placed in a plaster bed postoperatively. After 3 months each patient was fitted with a Minerva plaster jacket, which was worn for 4 to 6 weeks. Following this the patient was fitted with a molded, rigid collar, which was worn for an additional 3 to 6 months. ${ }^{32}$

In 1993 Jain and colleagues ${ }^{38}$ described a technique in which an occipitoaxis posterior wiring and fusion was performed for an atlantoaxial dislocation. Their patients presented with occipitalization of the atlas. In this unique modification of a wiring and onlay bone graft technique, the authors created a $3 \times 1-\mathrm{cm}$ horizontally oriented rectangular groove in the suboccipital bone $1 \mathrm{~cm}$ posterior to the foramen magnum. They built up a "bone bridge" along the posterior margin of the foramen magnum, which they referred to as an "artificial atlas." Conventional wiring and fusion was then performed between the artificial atlas and the C-2 laminae by using an interposed bone strut graft. Compressive forces were applied in the vertical plane with wire tightening.

\section{Locksley Intersegmental Tie-Bar Method}

The Locksley technique combines wire-and-bone and wire-and-plate strategies to achieve three-point fixation. Bilateral autograft rib struts are attached to twisted wires in the suboccipital bone, which have been passed through drill holes adjacent to a keyhole craniectomy. The ribs are secured to the cervical spine by pairs of sublaminar 
wires, which are tightened in a figure-eight pattern. A posterior T-plate is applied to the midline and is secured by wires passed through holes in the base of the spinous processes. In this fashion, a rigid three-point fixation is attained (Fig. 1).

\section{Use of Hooks}

An inverted hook occipital clamp system was originally described by Faure in 1998. In these procedures inverted hooks are inserted through a burr hole, which has been drilled in the squamous portion of the occipital bone. Burr holes are created in the suboccipital bone with a highspeed diamond drill. The positions of the burr holes are based on anatomical landmarks located $2 \mathrm{~cm}$ from the midline and $3 \mathrm{~cm}$ below the upper neck line. The diameters of the burr holes correspond to the widths of the hooks. The dura mater is dissected free from the underlying inner table. Occipital burr hole hooks are placed in the burr hole back to back. The laminar surfaces of the vertebrae onto which the hooks are to be secured are also prepared. Occipital hooks are selected with a contour to assure good purchase on the squamous portion of the occipital bone. The cervical hooks are positioned to create a lamina-lamina clamp construct. The rods are then contoured and installed. Fifteen patients with unstable occipitocervical junction lesions underwent internal fixation performed using this technique. Occiput-C3 fixation was performed in eight cases, occiput-C4 fixation in three cases, and occiput-C2, $-\mathrm{C} 5$, and -C6 in one case each. A double cervical clamp was adapted and one patient underwent an occiput-C7 fixation. Only a single cervical clamp was required in the other 14 patients. ${ }^{22}$

Paquis and associates ${ }^{58}$ also described an occipitocervical fixation in which occipital and interlaminar claws were used. Prebent rods are secured to the spine with hooks, which can then be tightened and positioned, creating claw constructs. Suboccipital burr holes are created with claws

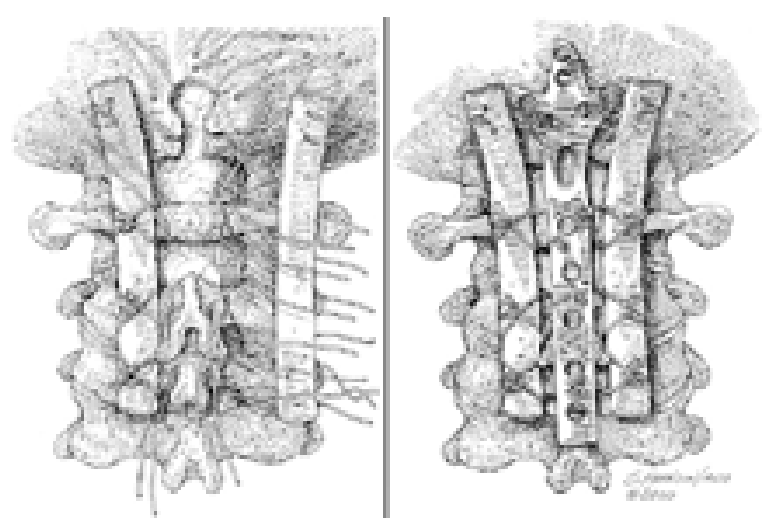

Fig. 1. Artist's drawing of an occipitocervical fusion made using an onlay rib autograft with suboccipital and sublaminar wires. Left: The keyhole craniectomy, which facilitates wire passage in the suboccipital region. This technique is used with numerous other suboccipitocervical wiring techniques as well. Right: The completed Locksley intersegmental tie-bar method, in which bilateral rib struts and a middle position posterior spinous/suboccipital plate are used to provide three-point fixation of the occipitocervical junction. secured using an elongated hole to allow for seating of the hook into the proximal portion of the burr hole. The option of screw fixation also exists if the occipital bone is more than $7 \mathrm{~mm}$ thick. Hooks can also be applied to the foramen magnum to create a "claw construct" in the suboccipital bone. Hooks are secured to the rods with screws.

\section{Rod-Wire Techniques}

Sonntag and Dickman ${ }^{74}$ have described a rod-and-wire technique for occipitocervical fusion in which a contoured 5/32-in threaded Steinmann pin is used. The rod is bent into a $U$ shape and then secondary contours are applied so that the closed end of the rod will rest against the suboccipital bone and the inferior free ends of the rod will match the cervical curvature over the segments that are to be included in the fusion. A threaded rod is selected to allow greater stability of the wires against the rod's surface and to resist migration of the rod or wires, which would result in vertical translation, telescoping, or settling of the construct. The foramen magnum is enlarged with rongeurs and two burr holes are placed in the suboccipital bone adjacent to the craniectomy. The dura mater is dissected free from the inner table, and wires are passed through the burr holes into the craniectomy defect.

For most wire techniques involving the suboccipital bone, the foramen magnum is enlarged to allow simpler and safer passage of wires because of the significant adherence of the dura mater and ligamentous structures to the bone at the rim of the foramen magnum. Either enlargement of the foramen magnum or keyhole craniectomies are described most commonly.

Braided or twisted wires are passed below the laminae bilaterally over all segments to be included in the fixation. The rod is then secured to the suboccipital bone and cervical spine by tightening the wires. Careful contouring of the rod and tightening of the wires is critical to ensure contact between the rod and spine at each level of the fusion. This assures the greatest degree of fixation and therefore stabilization of the spine. In cases in which the laminae have been removed or are incompetent, the wires can be placed through the facets and secured to the rod. Corticocancellous autografts are harvested from the iliac crest. Morcellized bone is placed over the levels to be fused after the cortex has been denuded using a drill. The facets are also cleared of soft tissue and packed to improve fusion further. In cases in which a laminectomy or a laminar defect is present, the struts of iliac crest cortical bone can be wired to the central portion of the Steinmann pin to preserve the dural decompression and to serve as a template for the fusion to occur. Fusion rates of $89 \%$ have been reported. ${ }^{74}$

The Ohio Medical Instruments loop has been used for occipitocervical fusion and was recently reviewed in a multicenter study involving 30 patients. This precontoured titanium implant was secured to the suboccipital bone by using midline and paramedian screws. These screws were individually measured based on the thickness of the patient's skull. Cervical fixation options include sublaminar wires or cables, interspinous wires or cables, transarticular screws, lateral mass screws, or combinations of screws, wires, and cables. The screws were connected to the Ohio Medical Instruments loop with lateral 
mass linkages. The occiput and cervical levels being fused were decorticated with the aid of a drill to facilitate fusion. Bone grafts, including structural and morcellized iliac crest autografts, or demineralized bone matrices were used..$^{72}$

The Hartshill-Ransford loop is described in a series of 43 patients with instability of the craniocervical junction. This contoured occipitocervical loop was secured with wire-and-cable constructs. Not all patients received autografts. ${ }^{47,62}$

Custom-formed Luque rods or the Luque-Hartshill system secured to the occiput and vertebrae with wires have also been used. Patients have been shown to maintain good cervical alignment, and bone fusion was achieved in the majority of patients. ${ }^{21,45}$

Fehlings and coworkers ${ }^{23}$ presented a technique of rigid occipitocervical arthrodesis in which a 5-mm malleable rod is secured to the suboccipital bone by a pair of wires that is passed through four suboccipital burr holes. Segmental fixation to the cervical spine is accomplished using Wisconsin interspinous wires, which occasionally are supplemented by sublaminar wires. Autologous bone grafts were used in all cases included in the study. Postoperative immobilization could include a cervical collar. Successful arthrodesis was achieved in all but one surviving patient.

\section{Pin-and-Wire Fixation}

A method of pin fixation, in which the pin is passed through the occipital external protuberance and the ends of the pin are used as fixation points for rods or wires, has also been described. Wires or rods attached to the free ends of the pin and the cervical spine secure the suboccipital bone to the cervical spine. This treatment has been successful in patients who have upper cervical instability due to cancer metastasis. ${ }^{43}$

\section{Screw-and-Plate or Screw-and-Rod Techniques}

An inverted Y-shaped screw plate, which also has been described, is used to secure the occipitocervical junction. Using this technique the plate is secured to $\mathrm{C} 1-2$ with transarticular screws and to the suboccipital bone with paramedian screws. The suboccipital bone varies in thickness, with a mean thickness of $14 \mathrm{~mm}$. Screws must be carefully selected to provide adequate purchase, yet avoid cerebellar injury. ${ }^{29}$ Utilizing the maximum screw length possible is critical because shorter screws do have decreased resistance to pullout. ${ }^{16}$ If stabilization is required below the C1-2 level, then lateral mass screws can be placed through additional holes in a longer plate to include these levels as well. ${ }^{74} \mathrm{~A}$ bone graft is again added to promote fusion. The $\mathrm{Y}$-shaped plate, in combination with transarticular screws, is an economically favorable alternative. Immediate postoperative stabilization is achieved and very low rates of pseudarthrosis have been reported. ${ }^{30}$

The "inside-outside" technique, described by Pait, et al. ${ }^{56}$ in 1999 , combines lateral mass plating with a bolt construct that is oriented from the epidural space outward. The lateral mass plate can be contoured to match the contour of the occipital bone as well as to match the cervical lordosis. The flathead screw is placed through a burr hole in the suboccipital calvaria with the threads facing outward. The suboccipital portion of the plate is then secured with nuts to secure the suboccipital screws. One case of nut loosening was reported. This technique also provides immediate fixation and does not rely on the posterior elements as anchor sites.

In 1999 Vale, et al. ${ }^{79}$ described a rigid occipitocervical fusion. The device that they used consisted of a plate secured to the atlantoaxial junction with transarticular screws. The plate extends superiorly to engage the occipital bone with screws. Lateral mass screws can also be included with the plate as it extends caudally, if additional segments of the cervical spine require fixation.

\section{Screw-and-Rod Fixation}

Several lateral mass screw and rod systems that are available for subaxial cervical spine fixation have the capability to attach to the suboccipital bone. These systems are easy to contour and provide rigid fixation (Fig. 2). Abumi and colleagues ${ }^{1}$ have also described an occipitocervical reconstruction in which pedicle screws and occipitocervical rod systems are used. These systems provide high fusion rates and a significant correction of malalignment.

\section{The C1-Occipital Condyle Screw}

In 2003 Gonzalez and associates ${ }^{27}$ evaluated a transarticular screw technique in which the occipital condyle is affixed to C-1. A 1.5-mm-diameter end-threaded steel guidewire was drilled from $\mathrm{C}-1$ into the occipital condyle. The entry point was at the midpoint of the posterior aspect of the lateral mass of $\mathrm{C}-1$, underneath the sulcus arteriosus. The middle aspect of the occipital condyle was used as an initial target for the trajectory of the guidewire. The trajectory was monitored on anteroposterior and lateral fluoroscopic images until the wire tip reached a point $1 \mathrm{~cm}$ rostral to the tip of the odontoid process. The guidewire was directed medially 10 to $20^{\circ}$ across the occipital condyle. This was monitored on the anteroposterior fluoroscopic image. A pilot hole, $30 \mathrm{~mm}$ deep, was then created

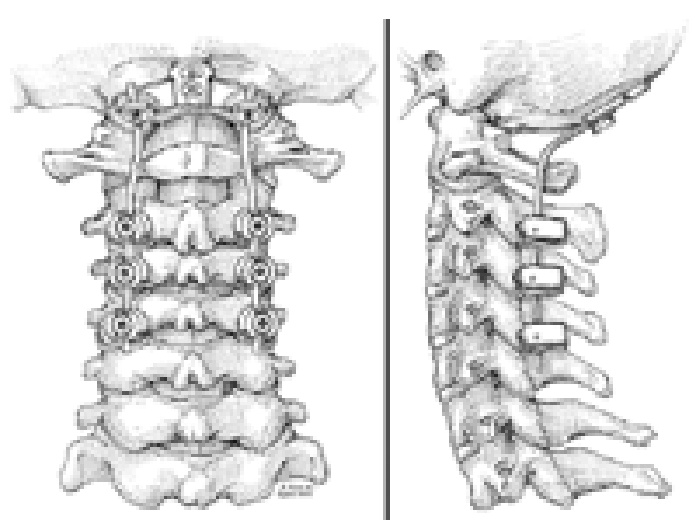

Fig. 2. Anteroposterior (left) and lateral (right) view of a typical rod-and-screw occipitocervical fixation device. The rod is secured to the subocciput by a buttress plate secured with screws anchored into the suboccipital midline. The rod is secured to C2-4 with lateral mass screws. In this example the posterior arch of $\mathrm{C}-1$ has not been included in the fixation. The rod can be contoured to allow optimization of the occipitocervical angle as well as that of the cervical lordosis. 
by using a 2.7-mm cannulated bit. The hole in the C-1 portion and the proximal portion of the condyle was widened using a 4-mm drill. A lag screw was then placed. By using a lag screw, the occipitocervical gap could be reduced. Although this was an in vitro biomechanical study, the authors do report the successful treatment of one 17year-old patient and provide 7 months of follow-up data in that case.

\section{Biomechanical Studies}

There are multiple studies in which the various occipitocervical fixation techniques have been evaluated. . $37,53,71^{2}$ Overall, most techniques do provide stability, at least in some planes of movement. Most methods proved to be susceptible to fatigue and loss of reduction over time. The methods noted to be the most stable were screw fixation techniques that included occiput-C2. These shorter segment fusions were noted not only to reduce the number of vertebral segments necessary to be included in the fusion, but also to provide superior immobilization, resistance to fatigue, and resistance to vertical settling compared with sublaminar methods. ${ }^{37}$ These observations were confirmed in a series in which lateral mass screws were compared with sublaminar wiring techniques as a point of cervical fixation in patients with rheumatoid arthritis. ${ }^{71}$ In another series there was an evaluation of sublaminar wiring-and-rod techniques; occipital screws with C-2 laminar claws and hooks and/or rod; occipital screws with foramen magnum screws and C1-2 transarticular screws and rods; occipital screws and C1-2 transarticular screws with a $\mathrm{Y}$ plate; and occipital screws and C-2 pedicle screws with rods. The authors' conclusion was also that occipitocervical stabilization attained using $\mathrm{C} 1-2$ transarticular screws or $\mathrm{C}-2$ pedicle screws was biomechanically advantageous compared with stabilization that relies on sublaminar wiring or hook constructs. Pedicle screw fixation demonstrated the greatest degree of stiffness among the five constructs that were tested..$^{53}$

The thickness of the posterior inferior occipital bone was measured relative to a $10 \times 5-\mathrm{cm}$ grid. The maximum thickness ranged from 11.5 to $15.1 \mathrm{~mm}$ in male patients and 9 to $12 \mathrm{~mm}$ in female patients at the level of the external occipital protuberance. The authors defined a zone of bone based on measurements from external landmarks, where the bone could be expected to be more than $8 \mathrm{~mm}$ thick. This zone extended laterally from the occipital protuberance $23 \mathrm{~mm}$ bilaterally and consisted mainly of dense cortical bone with minimal diploic bone. The locations of the dural sinuses are also described, based on measurements from external landmarks. The dural sinuses are situated beneath the thickest regions of the occiput and are at risk for a penetration injury during screw placement. Therefore, it is essential to determine preoperatively the thickness of the occipital bone. ${ }^{19}$

\section{ATLANTOAXIAL FUSION}

\section{Overview}

Fusion and instrumentation strategies that focus only on the atlantoaxial junction have followed a similar evolution. Although these constructs do not face the same requirements when the occiput (and therefore the occipito- cervical angle) is not a factor, significant mechanical strain must still be resisted. In extreme cases of atlantoaxial instability, particularly if the posterior arch of C-1, the lamina of $\mathrm{C}-2$, or the lateral masses or facets of $\mathrm{C} 1-2$ are significantly abnormal, fusion and instrumentation constructs are extended rostrally to include the suboccipital bone or caudally to include the subaxial cervical spine.

\section{Bone-Wire Techniques}

Gallie Fusion. The Gallie type of fusion, ${ }^{25}$ initially described in 1939, simply involves the placement of a notched bone graft between the dorsal portion of the arch of $\mathrm{C}-1$ and the posterior spinous process and medial laminar arches of C-2 (Fig. 3). This graft is secured by sublaminar wires, which pass beneath $\mathrm{C}-1$ and $\mathrm{C}-2$. The primary drawback of this technique is that it represents a single, midline point of fixation that is susceptible to rotational forces. ${ }^{25}$ In addition, concern exists when more than one spinal segment is spanned using sublaminar wires because of the increased risk of encroachment on neural elements within the spinal canal during the actual passage of wires as well as the risk of chronic encroachment of the wires over time. This is particularly significant in cases in which anterior translation of the atlas results in a decrease in spinal canal dimensions and a relative spinal canal stenosis. Therefore, although easy to perform, this method is not very stable and requires a rigid orthosis, preferably a halo, for postoperative immobilization. ${ }^{49}$

Brooks Fusion. The Brooks type of fusion, ${ }^{4}$ described in 1978, overcomes the rotational deficiencies of Gallie fusion by incorporating bilateral, interlaminar bone grafts (Fig. 4 upper). Again bilateral sublaminar wires, which have been passed under both $\mathrm{C}-1$ and $\mathrm{C}-2$, are used to secure the individual grafts. Notches can be placed in the bone graft to secure the position of the wire. By tightening the wire, compression can be applied to the graft. ${ }^{4}$ Modifications that have improved the results attained using this method include oversized autogenous iliac crest bone

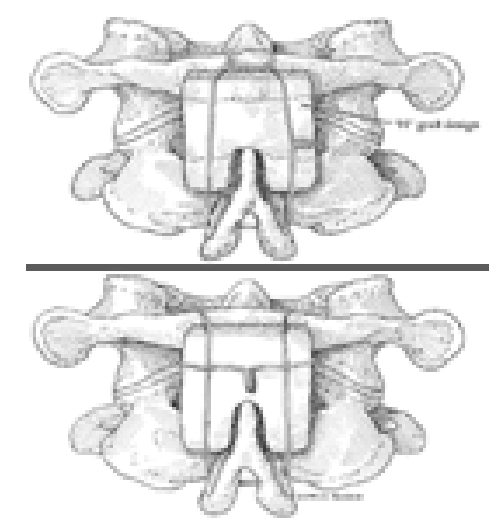

Fig. 3. Drawing showing a Gallie type of fusion with two variations. Upper: A single loop of wire around the posterior arch securing the onlay bone graft to the posterior arch of C-1 and the superior laminar surface of C-2. Lower: The double-loop technique with a wire around the arch of $\mathrm{C}-1$ again securing the onlay graft in place. Both examples eliminate the need for sublaminar wires at C-2. 


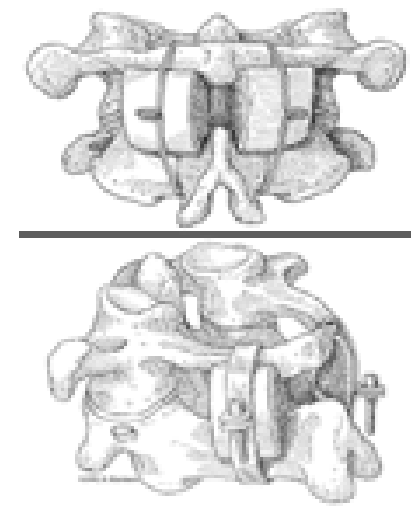

Fig. 4. Upper: Drawing showing a Brooks type of fusion with bilateral interlaminar bone grafts secured with C-1 and C-2 sublaminar wires. The bilateral fixation afforded by this technique better resists rotational forces. Lower: Halifax clamp technique in which bilateral interposition grafts are secured by the Halifax clamp construct.

grafts and the use of double strands of wire for each individual graft. ${ }^{49}$ The Brooks fusion method shares the disadvantage associated with the Gallie procedure of requiring multisegment sublaminar wires. Heavy-gauge singlestrand wires pose a significant danger of causing injury to the spinal cord during their passage. The evolution of braided cables has made the passage of these wires somewhat safer. ${ }^{26,36,73}$

Sonntag's Modified Gallie Fusion. In this modification the sublaminar wires under C-2 are eliminated and, instead, the spinous process of $\mathrm{C}-2$ serves as a fixation point. Intraoperatively, the $\mathrm{C} 1-2$ interlaminar space is widened. The inferior surface of the $\mathrm{C}-2$ spinous process is notched. A loop of wire is then passed sublaminarly under the $\mathrm{C}-1$ process in the caudorostral direction. An autograft or allograft strut is fashioned in a similar way to the Gallie procedure. The wire is then passed over the graft, which can be notched to accept and secure the wire. The loop is passed over the arch of C-2 and is secured to the undersurface of the spinous process that rests in the notch previously created. This secures the bone graft in the interlaminar space that is contained within the wire loop. The free ends of the wire are then brought over the C-2 laminar surface and secured either by twisting them or by being secured with a crimp device after an adequate tightness had been achieved. This connection secures the formerly free ends of the wire against the inferior surface of the $\mathrm{C}-2$ spinous process below the looped portion of the wire. Again, the use of braided multistrand wire facilitates the passage of the wires because of its decreased wire rigidity; this not only makes wire passage easier, with a lower rate of morbidity, but allows greater tightening and results in better fixation and a stronger construct. ${ }^{49}$

Locksley Intersegmental Tie-Bar Technique. The Locksley intersegmental tie-bar technique can also be used to fix the atlantoaxial articulation (Fig. 5). The grafts are secured with sublaminar wires that are twisted in a figure-eight fashion. The Locksley method differs from other onlay graft-wiring techniques because of the addition of a posterior stabilization plate, which is secured by wires to the posterior spinous process. In this fashion the Locksley method applies three-point fixation with immediate rigidity and resistance to all axes of movement. The Locksley method can be applied to any cervical segment and can also span the cervicothoracic junction. The autogenous rib graft can be cut cross-wise with a full-sized rib used bilaterally. For longer constructs, to avoid harvesting two ribs, the rib graft can be split in the midline and each half of the rib can be used separately. The rib, by its natural contour, is an ideal graft selection. An iliac autograft can also be used. ${ }^{80}$

\section{Methylmethacrylate and Pin Fixation}

Stabilization of the atlantoaxial region can be achieved with the addition of acrylic resins that are polymerized in situ, which provides immediate stability. These resins must be used cautiously and sparingly, however, because they do not promote fusion. Application of methylmethacrylate can impart immediate stability to the C1-2 interspace. Nevertheless, methylmethacrylate will not bond directly to bone and therefore, the acrylic construct must be "anchored" to the bone by applying either wires or pins. Several key technical points must be observed for this fusion to be successful. If wires are to be used, there must be adequate space around the wire so that the wire can be contained completely within the body of methylmethacrylate. Other fixation devices that have been described include Kirschner wires passed through the spinous processes or screws placed in the articular pillars. For inclusion of the arch of $\mathrm{C}-1$, screws are placed obliquely into the long axis of the arch, with the head protruding at least $4 \mathrm{~mm}$. An appropriate amount of acrylic must be applied to provide an adequate structural strength to resist the forces involved. The area must be keep free from blood and CSF until the acrylic has hardened. ${ }^{17,49}$ Great care must be taken while applying this method to assure that the exothermic reaction that is created when the acrylic is curing does not subject the spinal cord or nerve roots to elevated temperatures. In experienced hands this can be managed safely.

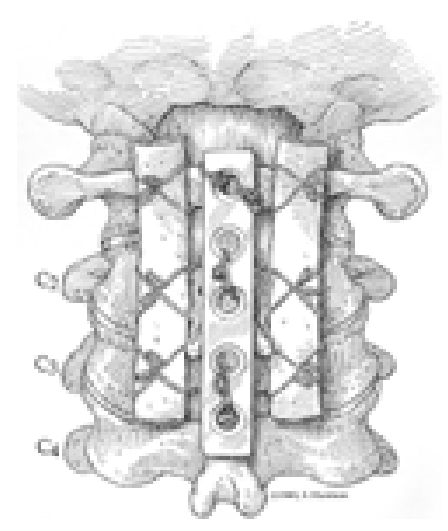

Fig. 5. Drawing showing the Locksley method in which sublaminar wires are used with bilateral onlay rib grafts, spinous process wires, and a posterior spinous process plate. Unlike the other sublaminar wiring techniques, the addition of the posterior spinous wires and plate creates a three-point fixation. 


\section{Interlaminar Clamp}

Claw-type constructs such as Halifax clamps or Knot's rods have also been applied to the C1-2 segment. The Halifax clamp was initially described by Tucker ${ }^{78}$ in 1975 (Fig. 4 lower). Halifax clamps have also been used successfully in lower cervical spinal segments, as documented by a long-term follow-up review. ${ }^{12,18,34}$ Using these techniques, immediate fixation is achieved and the risk associated with sublaminar wires is avoided. Bone grafts are again placed in the interlaminar space bilaterally, similar to a Brooks-type fusion. These bone grafts are secured under the interlaminar clamps. ${ }^{51}$ In most cases these devices are easy to apply, although difficulty can occur if the laminar hooks do not fit readily in place. Loosening of the screws and dislodgment of the clamps have been described. Newer clamps have an increased number of threads to reduce the risk of screw backout and loosening. Other solutions to this problem include the placement of acrylic over the screws and threads or destruction of the threads with a burr or clamp after the devices have been tightened. Overtightening has also been described and has resulted in increased angulation of the odontoid, causing ventral encroachment and possible compression of the spinal cord. The risk of this complication can be minimized by using bone grafts that have been carefully sized to prevent overcompression. ${ }^{49}$ Statham, et al. ${ }^{75}$ reported complications in 14 of 45 patients who underwent atlantoaxial arthrodesis. In 10 patients screw loosening occurred and in four patients one of the clamps disengaged. Nine patients $(20 \%)$ required a repeat operation. The unique anatomical features of the atlantoaxial motion segment were cited as an explanation for this widely observed failure rate at the level of $\mathrm{C} 1-2$. The posterior arch of $\mathrm{C}-1$ is more rounded, in contrast to the sharp edge of the subatlantal laminae. This creates a mechanically suboptimal interface between the arch and the clamp at C-1. In addition, it is difficult to achieve vertical alignment of the clamps because of the large spinous process of C-2. This results in angulation of the construct in the sagittal plane, which decreases the surface area of contact between the clamp and the arch of C-1. This may further increase the susceptibility of the constructs to disengagement during rotation. Loosening of the screws can compound this complication. ${ }^{75}$ Huang and $\mathrm{Chen}^{35}$ in 1996 reported on a series of 32 patients who underwent atlantoaxial fixation and arthrodesis with Halifax clamps. Contrary to other series, these authors had a $100 \%$ successful fusion rate. In their patients, however, a halo orthosis was applied to all patients for 3 months.

\section{Transarticular Screw Fixation}

A major advance in posterior $\mathrm{C} 1-2$ fixation was initially described by Magerl (Fig. 6). Fixation of the C1-2 lateral masses with transarticular screws provides immediate stabilization. The method does not require a complete or competent arch of $\mathrm{C}-1$ for success. In most cases an interspinous Gallie bone graft is placed between the posterior arch of $\mathrm{C}-1$ and the posterior spinous process and superior laminar surface of C-2. Careful preoperative planning is required, with thin-cut $\mathrm{CT}$ scans and $\mathrm{CT}$ reconstructions being used to confirm that adequate bone exists to allow passage of the screws without injury to the VAs. After the

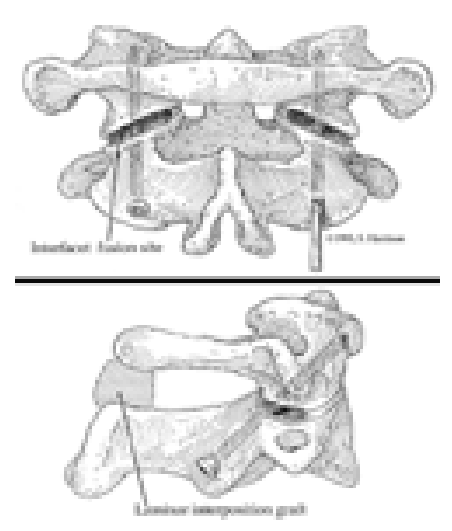

Fig. 6. Drawing showing a Magerl-type transarticular screw fixation. Screws are seen in their trajectory on both the anteroposterior (upper) and lateral (lower) views. On the lateral view the interspinous bone graft is demonstrated. With the addition of wires or hooks this would provide a three-point fixation.

screws have been passed, immediate fixation is attained. An interspinous Gallie bone graft is often used and may or may not be supplemented with wires. In this procedure the occiput and the posterior arches of $\mathrm{C}-1$, C-2, and C-3 are exposed subperiosteally. Passage of the wire, drill, and screw require a fairly "flat" angle and, frequently, secondary incisions need to be created in the upper thoracic region to obtain the required angle, thus avoiding the need to perform a much longer cervical incision. By exposing the superior edge of the C-2 lamina and the isthmus bilaterally, the medial surface of the C-2 pedicle can be palpated using a probe. The posterior surface of the C1-2 joint and capsule are then exposed laterally to the sulcus arteriosus of the C-1 arch. Fluoroscopic control is used to monitor the orientation of the drill. The drill entrance point is located on the inferior facet of C-2 $2 \mathrm{~mm}$ lateral from the medial edge and $3 \mathrm{~mm}$ above the caudal edge. With the aid of the fluoroscope, the trajectory is adjusted to exit $\mathrm{C}-2$ at the posterior edge of the superior articular surface, near the entrance of the C-2 pedicle. The lateral mass articulation is crossed so that the subarticular surface is entered at its posterior to middle third. The ideal trajectory orients the drill toward the anterior arch of $\mathrm{C}-1$. The drill orientation is maintained in the sagittal plane or angled $10^{\circ}$ medial to the sagittal plane. One preferred method consists of using two drills so that the initial drill can be left in place to stabilize the C1-2 relationship while the opposite side is accessed and the screw is placed. Instrumentation can then be placed on the initial side. If the VA is damaged, pulsatile bleeding will be seen and the procedure cannot be completed on the opposite side. The primary deficiency of this procedure occurs when an inadequate purchase is attained on C-1 or C-2 by the drill or screw. This can be minimized by careful patient selection, strict adherence to the procedural protocol, and a thorough understanding of the patient's unique 3D atlantoaxial anatomy. ${ }^{49}$

\section{Transarticular Screws With Claw}

Olerud and Olerud ${ }^{54}$ in 2001 described a new fixation device for C-1. Transarticular screws are passed through 
a plate adapted with an arm containing a claw that is fixed to the posterior arch of $\mathrm{C}$ - 1 . In this fashion the transarticular screw technique, which alone provides two-point fixation, is converted into a three-point fixation construct. In the cases described by these authors midline posterior wiring was not required.

\section{Titanium Mesh Cages and Transarticular Screws}

In 2002 Matsumoto, et al., ${ }^{48}$ described the use of titanium mesh cages in place of structural autograft in cases in which transarticular screws are used. In this procedure, the cages are filled with autograft and placed between the posterior arch of C-1 and the superior laminar surface of $\mathrm{C}-2$ bilaterally. The inferior surface of the posterior arch of $\mathrm{C}-1$ and the upper portion of the C-2 lamina are prepared to accept the cage by using a diamond-burr drill. The cages range in height from 8 to $10 \mathrm{~mm}$. These cages can be tightly secured with a titanium cable placed sublaminarly at $\mathrm{C}-1$ and $\mathrm{C}-2$. In the series described by Matsumoto, et al., a double cable was used; it was cut into two separate pieces after passage. Additional cancellous autograft bone chips were placed across the posterior arch of $\mathrm{C}-1$ and the lamina of $\mathrm{C}-2$ to supplement the fixation further. This technique provided a rigid fixation. Four of five patients underwent simultaneous placement of transarticular screws and posterior cage and wire fixation. In one pa-tient the cage was inserted and posterior wiring alone was performed because there was difficulty placing the transarticular screws. Traction was applied to facilitate cage placement and wire passage. No rigid orthosis was required and only a soft collar was used if necessary for postoperative wound-related pain. In all patients the fusion was successful.

\section{Fixation of C1-2 With Polyaxial Screws and Rods}

Harms and Melcher ${ }^{33}$ described a novel method of atlantoaxial stabilization in 2001. Polyaxial head screws are inserted into the lateral mass of C-1 and the pedicle of $\mathrm{C}-2$. These screws are secured by rods bilaterally. Using this technique $\mathrm{C} 1-2$ fixation can be attained in patients who are not candidates for transarticular screws because of fixed subluxation of C-1 on C-2 as well as in patients in whom the VA is in an aberrant location, which would preclude the passage of screws. In these patients $3.5-\mathrm{mm}$ polyaxial screws are inserted into the lateral masses of $\mathrm{C}-1$ and through the pars articularis into the pedicles of C-2. If necessary, a fluoroscopically guided reduction of the $\mathrm{C} 1-\mathrm{C} 2$ articulation can then be performed prior to the insertion of the $3-\mathrm{cm}$ rods. A cancellous onlay bone graft can be used as a supplement. No structural grafting or wiring is required. In a series of 37 patients no neural or vascular injury was reported. In all patients a solid fusion was attained. In some cases, if only temporary fixation was required, the implants could be removed. ${ }^{33}$ Resnick and Benzel ${ }^{64}$ in 2002 described a similar method in which screws are placed in the $\mathrm{C}-1$ and $\mathrm{C}-2$ pedicles bilaterally. Fixation was achieved by using a fixed-moment arm cantilever beam system. In their case report a single patient was presented in whom a transarticular screw fixation was not feasible.

\section{Biomechanical Studies}

Among wire techniques, with the exception of the Gallie procedure, adequate stability can be achieved. ${ }^{28}$ Richter and associates ${ }^{65}$ described a comparison of six methods including the Gallie technique alone, transarticular screws with Gallie fixation, transarticular screws alone, transarticular screws and an atlas claw, isthmus screws in the axis and an atlas claw, and lateral mass screws in the atlas and isthmus screws in the axis connected with rods. Their conclusions support previous observations that three-point fixation is superior to one- or two-point fixation. In this particular selection of techniques, the transarticular screws and the atlantal claw provided a rigid internal fixation that was not dependent on bone graft or sublaminar wiring. In cases in which transarticular screws were not feasible because of the patient's anatomy, isthmus screws with a claw or lateral mass screws with a midline fixation would be the next best alternative. Naderi and coworkers ${ }^{52}$ evaluated four combinations of cables, grafts, and screw fixation at $\mathrm{C} 1-2$. Transarticular screws again were more effective in preventing lateral bending and axial rotation than posterior cable graft constructs alone. Cable graft constructs do prevent flexion and extension better than stand-alone screw fixation techniques. Again, increasing the number of fixation points often will significantly decrease the rotation and translational movement, confirming that it is mechanically advantageous to include as many fixation points as possible. Reilly, et al., ${ }^{63}$ confirmed as well that transarticular screws are superior to wire techniques. Dickman, et al., ${ }^{15}$ evaluated four cable fixation methods. All wire techniques were ineffective with one Gallie fusion technique proving to be no better than an unfixed spine. The Brooks and interspinous methods were more effective than the Gallie methods; however, to attain adequate control of movement at $\mathrm{C} 1-2$ by using these posterior fixation techniques (two Gallie types, one Brooks, and interspinous wires), additional fixation is required in the form of a collar, a halo orthosis, or rigid internal fixation with transarticular screws.

\section{Overview}

\section{THE SUBAXIAL CERVICAL SPINE}

A number of methods used to secure the atlantoaxial junction can also be applied to the subaxial cervical spine.

\section{Onlay Bone and Wiring Techniques}

Cervical Facet Wiring. Wiring of the cervical facets has been widely used. Two techniques have been described. The first, described by Callahan and colleagues ${ }^{6}$ in 1977 , involves bilateral twisted wires and a bone graft. Holes are drilled in the inferior facets of the vertebrae to be stabilized bilaterally. Twisted 24-gauge wires are then passed through each of the holes and twisted around a corticocancellous iliac crest autograft. This method was originally described for postlaminectomy instability, but has also been used for posttraumatic instability. Immediate stabilization is not achieved using this method and a halo vest is required until fusion has occurred. ${ }^{6,11}$

In 1983 Cahill, et al., ${ }^{5}$ described, a wiring technique in which both the facet and spinous process are used. This 
technique can be used even when one or both facet joints have been injured. In this technique holes are again drilled bilaterally into the inferior facet of the upper vertebra to be fused. Twisted strands of 22- or 24-gauge wire are then passed through the holes and tied around the inferior spinous process of the segment to be stabilized. Bilateral wiring is performed, even when only unilateral facet injury is present. The authors contend that, in such injuries, spinous wiring alone is not adequate. The limitation of this technique is that it requires the stabilization of intact posterior elements of the inferior vertebra as well as the inferior facet of the superior vertebra. Failure of this technique is often related to a pullout of the wire through the relatively thin bone of the inferior facet. Both methods of cervical facet wiring have been largely replaced by lateral mass fixation, which is attained using either plates or rods. ${ }^{5,11}$

Interspinous Wiring. Interspinous wiring represents one of the oldest and most widely used methods of spinal wiring. This method is not effective if there is any injury to the posterior elements including the laminar arches or spinous processes. This represents a single point of fixation and, therefore, is not effective in resisting rotational forces because only a single, midline structure (the spinous process) is fixed. This technique is particularly useful with flexion deformity injuries and jumped facets. Although there are numerous variations of this technique, in general a hole is drilled through the base of the posterior spinous process at the superior level to be instrumented. Either single-strand or twisted wires, or braided cables are then passed through this hole and looped around the posterior spinous process of the inferior level in which instrumentation is to be placed. The wires are then tightened. The holes are situated closer to the rostral edge of the spinous process to allow the greatest mass of spinous process bone to resist wire pull-through either acutely during tightening or in the long term due to bone erosion. Often, the inferior surface of the spinous process is angled away from the superior vertebrae and can restrain the wire without risk of the loop slipping free from the process. If necessary, a notch can be created with a rongeur or cutting burr in the inferior surface of the posterior spinous process to stabilize the loop of wire. Again, a minimal degree of bone removal is optimal to allow the greatest volume of bone possible to reduce the risk of wire pull-through. Either split corticocancellous bone struts or morcellized corticocancellous bone chips are then placed along the lateral masses and laminar arches of the segments to be fused. Often these surfaces are denuded of cortex by using a burr or rongeur to enhance fusion. In most cases the facet joint can be cleared of soft tissue with a curette and morcellized bone graft can then be packed in the facet to facilitate the fusion further.

In some variations of this technique, rigid (usually single-strand) wires are used. The free ends of the wires can be bent laterally to lay over the bone graft and help stabilize the position of the corticocancellous struts until fusion occurs. ${ }^{11}$

This technique can be modified if the spinous process is damaged or if there is damage to the intervertebral disc. In these cases two motion segments can be stabilized with wires securing the posterior spinous process of the segment above the level of the posterior spinous process injury and extended to the inferior level. Cooper ${ }^{11}$ also described this variation in cases of VB injury, but recommended the inclusion of the posterior spinous process of the fractured VB in the wiring construct as well. This technique is also used when the fractured posterior spinous process is "skipped," with stabilization of both the undamaged process above and the posterior spinous process of the inferior VB. 7,11

Sublaminar Wires. Sublaminar wires are also used in the subaxial cervical spine. Great care must be taken because of the relative enlargement of the middle of the cervical spinal cord and the relatively limited spinal canal dimensions at these levels. Sublaminar wires are most commonly used to affix either an onlay graft, contoured rods, or other fixation devices to the spine. Although sublaminar wires are often criticized as dangerous because of the risks of dural injury and spinal cord compression or injury, the results of many series confirm that these wires can be placed safely and are a cost-effective alternative to other fixation systems. ${ }^{26}$ Advances in wire technology have overcome the rigidity issues of single-stand heavier-gauge wire. These have been replaced by flexible cables, which are safer to pass and have a higher degree of flexibility. In addition, the biomechanical strength of these braided cables is superior to other wire constructs. The flexibility of the cable simplifies insertion and improves tension adjustment. ${ }^{36,82}$

Methylmethacrylate and Wire. Stabilization with methylmethacrylate secured by wires is also effective in the subaxial cervical spine. In one series, methylmethacrylate and wire were used in the midline and struts were placed laterally; good results were reported. ${ }^{3}$

Wire-Rod Techniques. The Hartshill rectangle, a modification of the Luque rod, is a device used in the cervical spine. Such devices are preformed rectangles that eliminate the need of bending rods to form rectangles, which is required when using other systems such as the Luque rod system. The rectangles are available in various sizes and an appropriate length can thus be chosen. The rectangle is placed on the spine so that the upper horizontal bar of the rectangle lies above the superior spinous process of the uppermost segment to be stabilized and the inferior horizontal bar of the rectangle fits beneath the most inferior spinous process to be stabilized. The rectangle can be contoured to achieve the appropriate lordosis. The rectangle is then affixed to the posterior aspect of the spine with sublaminar wires. In cases in which sublaminar wires are not feasible, some modifications of the technique provide for transspinous process wires to secure the rods. ${ }^{11}$

Interspinous fusion performed using wave-shaped rods fashioned from Kirschner wires with spinous process wire fixation for posterior cervical subaxial stabilization has been described by Onari and colleagues. ${ }^{55}$ The alignment of the spine is adjusted to match the cervical alignment that permitted the flow of contrast agent on a preoperative myelogram. The rods are inserted after administration of local anesthetic. This is done as a palliative procedure and is reserved for patients who are poor surgical candidates. 
Kirchner Wire Fixation. In 1985 Davey, et al., ${ }^{14}$ described the "Dewar procedure," an alternative method of stabilization to be used in the cervical spine. Two corticocancellous bone grafts are harvested from the posterior iliac crest. These grafts should be 15 to $20 \mathrm{~mm}$ wide and their lengths should be suitable for the number of segments that will be fused. The grafts are predrilled with threaded 2-mm-diameter Kirschner wires, which are introduced percutaneously through the paraspinal muscles, the predrilled graft, the base of the spinous process, and through the second predrilled graft, which is located on the contralateral side of the spinous process. The wire is cut off, leaving $1 \mathrm{~cm}$ of wire protruding from the graft on each side. An 18-gauge wire is then used in Gallie fashion to secure the wires. A loop is formed around the inferior spinous process. The two ends of the 18-gauge wire are brought cephalad around the Kirschner wires and then caudally to the point at which they are tied anterior to the distal spinous process. Cancellous bone chips are packed around the fusion site as well. Patients are maintained in a soft collar postoperatively.

\section{Laminar Clamps}

Although the Halifax clamp is associated with a significant failure rate when used to treat atlantoaxial instability, a number of series have confirmed the efficacy of the construct in the lower cervical spine (below C-3). ${ }^{2}$ Statham, et al. ${ }^{75}$ have described a $100 \%$ success rate in patients in whom instrumentation was used in the lower cervical spine. In the subaxial cervical spine, the more rounded blade, designed for the posterior arch of $\mathrm{C}-1$, is replaced by the more sharply angled blades that are better suited to accept the superior surface of the laminar arches of vertebra below $\mathrm{C}-3$.

\section{Lateral Mass Plates and Screws}

Lateral mass plates, originally described by Roy-Camille and colleagues, ${ }^{67,68}$ provide immediate stability of the cervical spine without the need for an intact lamina or spinous process (Fig. 7). No complex orthosis such as a halo device is required. ${ }^{11,67,68}$ Lateral mass plates are effective in injuries involving the vertebrae, facet, and ligamentous detachments, particularly if the posterior elements, such as the lamina and posterior spinous processes, are also damaged. Patients with significant osteoporosis or metabolic diseases of the bone may not be adequate candidates because there may be screw pullout and failure to maintain corrections in alignment. Plates are fixed to the lateral masses with screws. Screw entry points are determined by identifying the superoinferior and rostrocaudal boundaries of the lateral mass. Vertical and horizontal lines bisecting the midpoints of the mediolateral and superoinferior margins of the lateral mass are then used to identify the middle position. An awl is used to make a hole in the center of the lateral mass to anchor a drill bit. The drill is directed perpendicular to the spine in the superoinferior plane and 10 to $30^{\circ}$ lateral in the mediolateral plane. The drill is advanced to the depth appropriate for the length of the screw that is selected for the particular patient. The orientation of the drill laterally is to assure that drill trajectory is lateral to the foramen transversarium and the VA. The plates will either have multiple (variable

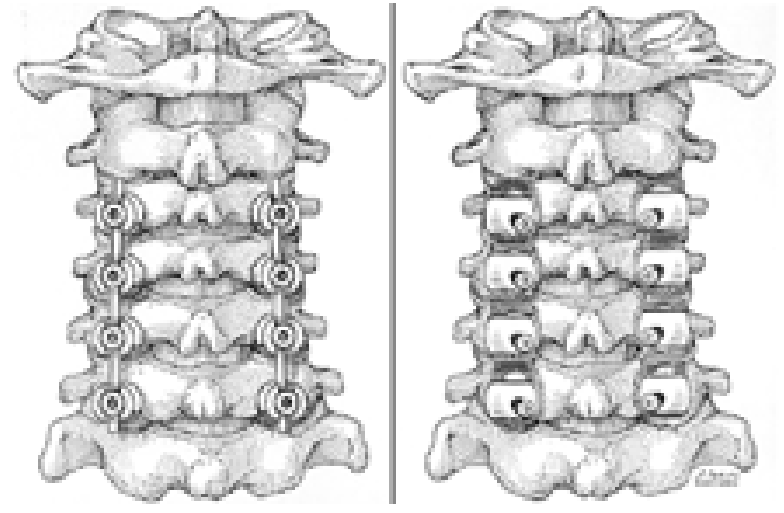

Fig. 7. Posterior views of the cervical spine demonstrating a rod-and-screw construct (left) and a lateral mass plate construct (right), both of which extend from C-3 to C-6. Polyaxial head screw-and-rod constructs allow for limitless positioning options of the lateral mass screws. The lateral mass plate demonstrated is one method by which variable screw positions can be selected with screws placed through an underlying elongated hole.

screw position) notches to allow multiple options for screw placement, overlying screw directing channels on a textured plate that allow multiple position alternatives, or predetermined screw holes placed 13.5 to $15 \mathrm{~mm}$ apart. The plates can be contoured without difficulty to either match the cervical lordosis or, in cases in which a deformity is being corrected, to restore cervical lordosis to the desired degree. ${ }^{11}$

In 2003 Wang, et al. ${ }^{81}$ described a minimally invasive method of insertion of lateral mass screws, which is accomplished using a tubular dilator retractor system.

\section{Hook Plates}

A hook plate has been described by Magerl, et al. ${ }^{46}$ for stabilization of one to two motion segments in the subaxial cervical spine. This construct consists of a standard lateral mass plate with one or two holes and a hook on one end. The hook is designed to engage the inferior aspect of the lamina of the lower vertebral segment to be stabilized. The hook plate is contoured to allow it to fit against the posterior surface of the vertebrae to be stabilized. Lateral mass screw holes are then placed. An $\mathrm{H}$-graft is placed in the interspinous space between the posterior spinous process of the vertebrae being stabilized. At this time the screws are inserted into the holes, securing the plate. There is significant dependency on the operator when using this method. The contour of the hook plate must be precisely formed to assure adequate purchase on the spine. This makes hook plates technically more difficult to use than straightforward lateral mass plates. Fractures of the posterior elements that would be contained by the hook would preclude the use of this device. ${ }^{11,46}$

\section{Transarticular Screws}

Transarticular screw fixation, which is highly successful at the atlantoaxial interspace, has also been described in the middle and lower cervical spine. Takayasu, et al., ${ }^{77}$ described, in 2003, the use of transarticular screws in 25 
patients with a total of 81 screws placed. The location of the VA and the nerve roots in the subaxial cervical spine simplify the placement of screws at these levels. At this level the neural and vascular elements are anterior to the articular pillars. Screw insertion is oriented from the articular pillar, with the screw directed anteriorly and caudally to penetrate the facet joint and the anterior cortex of the articular pillar parallel to this sagittal plane. This is performed under lateral fluoroscopic guidance. In 19 patients the transarticular screw served as an anchor and was used in combination with posterior cervical instrumentation. No complications with screw placements were described. Fusion was achieved in all patients. Biomechanical strength is increased due to the penetration of four cortical surfaces with the passage of screws using this technique.

Cigliano, et al., ${ }^{8}$ also described the use of transarticular screws as a fixation point for a posterior cervical plate fixation system. In this study 26 patients underwent treatment. Three cervical motion segments were immobilized in 15 patients, four segments in nine patients, and five segments in two patients. No complications and no mechanical failures were reported.

\section{Screw-and-Rod Systems}

Screw-and-rod systems used in the cervical spine provide the advantage of multiple fixation points and unlimited flexibility as to orientation and location of the screws (Fig. 7). Hooks for sublaminar anchoring can also be connected to the rods, if needed. Cross-linking devices enhance biomechanical stability and can allow for missed segments if the individual patient's anatomy precludes placement of a screw or a hook at a specific level..$^{10,39}$

\section{Biomechanical Studies}

Cervical biomechanical testing reveals that, in most cases, motion can be successfully limited in at least one plane of movement. Nevertheless, in general sublaminar, facet, and spinous process wiring constructs are less stable than lateral mass plates or rods with screw fixation. A comparison of unicortical and bicortical lateral mass screw fixation revealed no significant difference in pullout strength between unicortical and bicortical case screws, but there was a significant decrease in complications in patients who received unicortical placed screws. A comparison of rod and plate constructs demonstrated an increased rigidity in the rod constructs. When cables were used, multistrand cables were determined to be superior to conventional single-strand wires; however, there were no detectable differences in the type of material that was used-stainless steel, titanium, or polyethylene-type cables. In a review of six different fixation constructs, Weis, et al. ${ }^{83}$ confirmed that the posterior cervical plate has the greatest stability when compared with the other constructs tested. . $^{31,50,57,70,83}$

The use of transfacet screws in the lumbar spine has been described extensively. It has been evaluated in cadaveric cervical spines. Transfacet screws were found to be equal or better than lateral mass screws with respect to pullout strength. Transfacet screws could potentially of- fer the option of an additional point of fixation in cases in which additional fixation points are desirable or in cases in which lateral mass screws have been stripped, have failed, or are not feasible. ${ }^{42}$

Pedicle screw fixation of the subaxial cervical spine has been discussed. Although there does appear to be a slight biomechanical advantage to using these screws, it is more difficult to place them and a higher risk of morbidity is associated with their use. In experienced hands pedicle screws can be placed safely. ${ }^{44}$

\section{AUTOGRAFT BONE}

A key component of all fusions, regardless of what instrumentation technology is used, is the bone graft. Although multiple bone graft options are now available to the spine surgeon, autograft remains the preferred material in most occipitocervical, atlantoaxial, and subaxial cervical fusions. The most common autografts currently in use include iliac crest and rib. Sawin, et al. ${ }^{69}$ reviewed the fusion and donor site morbidity rates associated with autograft rib and iliac crest bone grafts that were obtained for posterior cervical fusion procedures. A retrospective review was conducted in more than 600 patients from whom autograft bone had been harvested. Three hundred patients underwent rib harvest and the other 300 underwent iliac crest graft harvest. In the iliac crest graft harvest group, harvesting was performed for ultimate posterior fusion in 52 patients. Rib grafts were used for occipitocervical fusion (196 patients), atlantoaxial fixation (35 patients), and subaxial cervical fixation (69 patients). Iliac crest grafts were used for occipitocervical fusion (28 patients), atlantoaxial fusion (10 patients), and subaxial cervical fusion (14 patients). Among patients who underwent posterior fusion, the fusion rates were $98.8 \%$ in those who received rib grafts and $94.2 \%$ in those who received iliac crest graft. The graft morbidity rate was greater in patients who received iliac crest grafts than in those who received rib grafts. The donor site morbidity rate for rib graft harvest was $3.7 \%$ and included pneumonia, persistent atelectasis, and superficial wound dehiscence. No case of pneumothorax, intercostal pain, or chronic chest wall pain was described. The iliac crest graft morbidity rate was $25.3 \%$ and usually consisted of chronic donor site pain, although wound dehiscence, pneumonia, meralgia paresthetica, hematoma, and iliac spine fracture were also reported. Even with the exclusion of chronic pain as an instance of morbidity, the rate of morbidity associated with iliac crest harvest still exceeded that associated with rib harvest in a statistically significant way. Overall, however, both sites were considered safe for autograft harvest. ${ }^{69}$

The occipital calvarial bone has also been used as a fusion source. Robertson and Menezes ${ }^{66}$ have described the use of an autologous occipital calvarial bone graft obtained from the same surgical incision during occipitocervical fusion surgery. These surgeons use a split-thickness graft in conjunction with a loop-and-cable construct. In most cases the patients had rheumatoid arthritis. A micro-air impactor was used to harvest the occipital bone. No complications related to graft procurement were noted. Bone fusion was achieved in 22 patients. 


\section{CONCLUSIONS}

In cases of craniocervical, atlantoaxial, and subaxial cervical instability, the primary goal of all the procedures described in this review paper is to restore and preserve alignment, decompress the neural elements, resist forces in all axes of movement, and provide the optimal environment for bone fusion to occur. In the absence of adequate bone fusion, all instrumentation constructs will ultimately fail. Numerous methods have been developed over time and, within each of these, numerous modifications have been described. Many older, "simpler" techniques continue to be widely used with good success. Spine surgeons who treat patients in these areas must be completely familiar with the anatomical and biomechanical relationships of the structures that are involved. A careful analysis of the pathological process and an understanding of the procedures required to achieve decompression, alignment, immobilization, and fusion are essential. An understanding of the biomechanical limitations of the construct that is selected is necessary to ensure that an appropriate external orthotic support is used to enhance the chances of fusion with any of the methods discussed. Many newer techniques have potential for significant morbidity if performed incorrectly and "hands-on" experience in a cadaver setting or supervised course are invaluable. The selection of a specific fixation procedure must be based on the individual surgeon's experience and the technologies available. Overall, the trend toward smaller, stronger, lower-profile constructs capable of providing multiple points of fixation yield stronger stabilization with an enhanced likelihood of successful fusion. The rapidly increasing number of spine surgeons experienced in the application of these techniques will yield greater clinical experience in the future. The patient benefits by having an immediate correction of the pathological processes that imperil the neural and vascular structures that are involved. Earlier diagnosis and correction based on a higher level of surveillance, earlier detection resulting from better imaging methods, and surgery associated with lower morbidity will improve overall outcomes. With stronger internal fixation, minimal if any external bracing is required and, if required, for a shorter duration. Minimally invasive percutaneous and endoscopic techniques coupled with advances in image guidance technology hopefully may further decrease the complexity and morbidity of these procedures.

\section{References}

1. Abumi K, Takada T, Shono Y, et al: Posterior occipitocervical reconstruction using cervical pedicle screws and plate-rod systems. Spine 24:1425-1434, 1999

2. Aldrich EF, Weber PB, Crow WN: Halifax interlaminar clamp for posterior cervical fusion: a long-term follow-up review. J Neurosurg 78:702-708, 1993

3. Awasthi D, Voorhies RM: Posterior cervical fusion with methylmethacrylate, wire, and bone: technical note. Surg Neurol 42: 259-264, 1994

4. Brooks AL, Jenkins EB: Atlanto-axial arthrodesis by the wedge compression method. J Bone Joint Surg Am 60:279-284, 1978

5. Cahill DW, Bellegarrigue R, Ducker TB: Bilateral facet to spinous process fusion: a new technique for posterior spinal fusion after trauma. Neurosurgery 13:1-4, 1983
6. Callahan RA, Johnson RM, Margolis RN, et al: Cervical facet fusion for control of instability following laminectomy. J Bone Joint Surg Am 59:991-1002, 1977

7. Capen DA, Garland DE, Waters RL: Surgical stabilization of the cervical spine. A comparative analysis of the anterior and posterior spine fusions. Clin Orthop 196:229-237, 1985

8. Cigliano A, De Falco R, Scarano E, et al: A new instrumentation for posterior stabilization of cervical traumatic instability. $\mathbf{J}$ Neurosurg Sci 42:101-109, 1998

9. Cone W, Turner WG: The treatment of fracture-dislocations of the cervical vertebrae by skeletal traction and fusion. J Bone Joint Surg 19:584-602, 1937

10. Cooper PR: The Axis Fixation System for posterior instrumentation of the cervical spine. Neurosurgery 39:612-614, 1996

11. Cooper PR: Posterior stabilization of the cervical spine. Clin Neurosurg 40:286-320, 1993

12. Cybulski GR, Stone JL, Crowell RM, et al: Use of Halifax interlaminar clamps for posterior C1-C2 arthrodesis. Neurosurgery 22:429-431, 1988

13. Dandy WE: Roentgenography of the brain after the injection of air into the spinal canal. Ann Surg 70:397-403, 1919

14. Davey JR, Rorabeck CH, Bailey SI, et al: A technique of posterior cervical fusion for instability of the cervical spine. Spine 10:722-728, 1985

15. Dickman CA, Crawford NR, Paramore CG: Biomechanical characteristics of C1-2 cable fixations. J Neurosurg 85: 316-322, 1996

16. Dickman CA, Sonntag VKH, Marcotte PJ: Techniques of screw fixation of the cervical spine. BNI Q 8:9-26, 1992

17. Duff TA, Kahn A, Corbett JE: Surgical stabilization of cervical spinal fractures using methyl methacrylate. Technical considerations and long-term results in 52 patients. J Neurosurg 76: 440-443, 1992

18. Duthel R, Brunon J, Jurine N, et al: Utilisation du matérial de Knodt dans les instabilités atloïdo-axoïdiennes. Lyon Chirurg 92:52-57, 1986

19. Ebraheim NA, Lu J, Biyani A, et al: An anatomic study of the thickness of the occipital bone. Implications for occipitocervical instrumentation. Spine 21:1725-1730, 1996

20. Elia M, Mazzara JT, Fielding JW: Onlay technique for occipitocervical fusion. Clin Orthop 280:170-174, 1992

21. Ellis PM, Findlay JM: Craniocervical fusion with contoured Luque rod and autogeneic bone graft. Can J Surg 37:50-54, 1994

22. Faure A, Monteiro R, Hamel O, et al: Inverted-hook occipital clamp system in occipitocervical fixation. Technical note. $\mathbf{J}$ Neurosurg (Spine 1) 97:135-141, 2002

23. Fehlings MG, Errico T, Cooper P, et al: Occipitocervical fusion with a five-millimeter malleable rod and segmental fixation. Neurosurgery 32:198-208, 1993

24. Foerster O: Die Leitungsbahnen des Schmerzgefühls und die chirurgische Behandlung der Schmerzzustände. Berlin: Urban \& Schwarzenburg, 1927

25. Gallie WE: Fractures and dislocations of the cervical spine. Am J Surg 46:495-499, 1939

26. Geremia GK, Kim KS, Cerullo L, et al: Complications of sublaminar wiring. Surg Neurol 23:629-635, 1985

27. Gonzalez LF, Crawford NR, Chamberlain RH, et al: Craniovertebral junction fixation with transarticular screws: biomechanical analysis of a novel technique. J Neurosurg (Spine 2) 98:202-209, 2003

28. Grob D, Crisco JJ III, Panjabi MM, et al: Biomechanical evaluation of four different posterior atlantoaxial fixation techniques. Spine 17:480-490, 1992

29. Grob D, Dvorak J, Panjabi M, et al: Posterior occipitocervical fusion. A preliminary report of a new technique. Spine 16 (Suppl 3):S17-S24, 1991

30. Grob D, Schutz U, Plotz G: Occipitocervical fusion in patients with rheumatoid arthritis. Clin Orthop 366:46-53, 1999

31. Grubb MR, Currier BL, Stone J, et al: Biomechanical evaluation 
of posterior cervical stabilization after a wide laminectomy. Spine 22:1948-1954, 1997

32. Hamblen DL: Occipito-cervical fusion: Indications, technique and results. J Bone Joint Surg Br 49:33-45, 1967

33. Harms J, Melcher RP: Posterior C1-C2 fusion with polyaxial screw and rod fixation. Spine 26:2467-2471, 2001

34. Holness RO, Huestis WS, Howes WJ, et al: Posterior stabilization with interlaminar clamp in cervical injuries: technical note and review of the long-term experience with the method. Neurosurgery 14:318-322, 1984

35. Huang CI, Chen IH: Atlantoaxial arthrodesis using Halifax interlaminae clamps reinforced by vest immobilization: a long-term follow-up experience. Neurosurgery 38:1153-1157, 1996

36. Huhn SL, Wolf AL, Eckland J: Posterior spinal osteosynthesis for cervical fracture/dislocation using a flexible multistrand cable system: technical note. Neurosurgery 29:943-946, 1991

37. Hurlbert RJ, Crawford NR, Choi WG, et al: A biomechanical evaluation of occipitocervical instrumentation: screw compared with wire fixation. J Neurosurg (Spine 1) 90:84-90, 1999

38. Jain VK, Takayasu M, Singh S, et al: Occipital-axis posterior wiring and fusion for atlantoaxial dislocation associated with occipitalization of the atlas. Technical note. J Neurosurg 79: 142-144, 1993

39. Jeanneret B: Posterior rod system of the cervical spine: a new implant allowing optimal screw insertion. Eur Spine J 5: 350-356, 1996

40. Juvara E, Dimitriu V: Luxation atloïdo-axoïdienne avec phénomènes compressifs, Opération secondaire. Lyon Chirurg 25: 668-670, 1928

41. Kahn EA, Yglesias L: Progressive atlanto-axial dislocation. JAMA 105:348-352, 1935

42. Klekamp JW, Ugbo JL, Heller JG, et al: Cervical transfacet versus lateral mass screws: a biomechanical comparison. J Spinal Disord 13:515-518, 2000

43. Laohacharoensombat W, Suphachatwong C: Occipital pin for rigid occipitocervical fixation in upper cervical metastasis. Bull Hosp Jt Dis Orthop Inst 50:20-26, 1990

44. Ludwig SC, Kramer DL, Vaccaro AR, et al: Transpedicle screw fixation of the cervical spine. Clin Orthop 359:77-88, 1999

45. MacKenzie AI, Uttley D, Marsh HT, et al: Craniocervical stabilization using Luque/Hartshill rectangles. Neurosurgery 26: 32-36, 1990

46. Magerl F, Grob D, Seemann D: Stable dorsal fusion of the cervical spine (C2-TH1) using hook plates, in Kehr P, Weidner A (eds): Cervical Spine I: Strasbourg 1985. New York: Springer-Verlag, 1987, pp 217-221 (Reference unverified)

47. Malcolm GP, Ransford AO, Crockard HA: Treatment of nonrheumatoid occipitocervical instability. Internal fixation with the Hartshill-Ransford loop. J Bone Joint Surg Br 76: 357-366, 1994

48. Matsumoto M, Chiba K, Tsuji T, et al: Use of a titanium mesh cage for posterior atlantoaxial arthrodesis. Technical note. J Neurosurg (Spine 1) 96:127-130, 2002

49. McDonnell DE, Harrison SJ: Posterior atlantoaxial fusion: indications and techniques, in Hitchon PW, Traynelis VC, Rengachary SS (eds): Techniques in Spinal Fusion and Stabilization. New York: Thieme, 1995, pp 92-106

50. Mihara H, Cheng BC, David SM, et al: Biomechanical comparison of posterior cervical fixation. Spine 26:1662-1667, 2001

51. Moskovich R, Crockard HA: Atlantoaxial arthrodesis using interlaminar clamps. An improved technique. Spine 17:261-267, 1992

52. Naderi S, Crawford NR, Song GS, et al: Biomechanical comparison of $\mathrm{C} 1-\mathrm{C} 2$ posterior fixations. Cable, graft, and screw combinations. Spine 23:1946-1956, 1998

53. Oda I, Abumi K, Sell LC, et al: Biomechanical evaluation of five different occipito-atlanto-axial fixation techniques. Spine 24: 2377-2382, 1999

54. Olerud S, Olerud C: The $\mathrm{C} 1$ claw device: an new instrument for C1-C2 fusion. Eur Spine J 10:345-347, 2001
55. Onari K, Toguchi A, Kondo S, et al: Cervical posterior fusion with wave-shaped rod under local anesthesia for cervical spondylotic myelopathy: review of 12 patients. Spine 26: 2334-2339, 2001

56. Pait TG, Al-Mefty O, Boop FA, et al: Inside-outside technique for posterior occipitocervical spine instrumentation and stabilization: preliminary results. J Neurosurg (Spine 1) 90:1-7, 1999

57. Papagelopoulos PJ, Currier BL, Neale PG, et al: Biomechanical evaluation of posterior screw fixation in cadaveric cervical spines. Clin Orthop 411:13-24, 2003

58. Paquis $\mathrm{P}$, Breuil V, Lonjon M, et al: Occipitocervical fixation using hooks and screws for upper cervical instability. Neurosurgery 44:324-331, 1999

59. Patwardhan RV, Hadley MN: History of surgery for ruptured disk. Neurosurg Clin N Am 12:173-179, 2001

60. Preul MC, Feindel W: A history of brain imaging technology in neurosurgery. Neurosurg Clin N Am 12:127-143, 2001

61. Rand CW: The Neurosurgical Patient; His Problems of Diagnosis and Care. Springfield, IL: Charles C Thomas, 1944

62. Ransford AO, Crockard HA, Pozo JL, et al: Craniocervical instability treated by contoured loop fixation. J Bone Joint Surg Br 68:173-177, 1986

63. Reilly TM, Sasso RC, Hall PV: Atlantoaxial stabilization: clinical comparison of posterior cervical wiring technique with transarticular screw fixation. J Spinal Disord Tech 16: 248-253, 2003

64. Resnick DK, Benzel EC: C1-C2 pedicle screw fixation with rigid cantilever beam construct: case report and technical note. Neurosurgery 50:426-428, 2002

65. Richter M, Schmidt R, Claes L, et al: Posterior atlantoaxial fixation: biomechanical in vitro comparison of six different techniques. Spine 27:1724-1732, 2002

66. Robertson SC, Menezes AH: Occipital calvarial bone graft in posterior occipitocervical fusion. Spine 23:249-255, 1998

67. Roy-Camille R, Saillant G, Judet T, et al: Traumatismes Recents Des Cinq Dernieres Vertebres Cervicales Chez L'Adulte (Avec et sans complication neurologique). Sem Hop 59: 1479-1488, 1983

68. Roy-Camille R, Saillant G, Verteaux D, et al: Early management in spinal injuries, in McKibbon B (ed): Recent Advances in Orthopedics. Edinburgh: Churchill-Livingstone, 1979, pp 57-87 (Reference unverified)

69. Sawin PD, Traynelis VC, Menezes AH: A comparative analysis of fusion rates and donor-site morbidity for autogeneic rib and iliac crest bone grafts in posterior cervical fusions. J Neurosurg 88:255-256, 1998

70. Seybold EA, Baker JA, Criscitiello AA, et al: Characteristics of unicortical and bicortical lateral mass screws in the cervical spine. Spine 24:2397-2403, 1999

71. Shad A, Shariff SS, Teddy PJ, et al: Craniocervical fusion for rheumatoid arthritis: comparison of sublaminar wires and the lateral mass screw craniocervical fusion. Br J Neurosurg 16: 483-486, 2002

72. Singh SK, Rickards L, Apfelbaum RI, et al: Occipitocervical reconstruction with the Ohio Medical Instruments Loop: results of a multicenter evaluation in 30 cases. J Neurosurg (Spine 3) 98:239-246, 2003

73. Songer MN, Spencer DL, Mayer PR Jr, et al: The use of sublaminar cables to replace Luque wires. Spine 16 (Suppl 8): S418-S421, 1991

74. Sonntag VKH, Dickman CA: Craniocervical stabilization. Clin Neurosurg 40:243-272, 1993

75. Statham P, O'Sullivan M, Russell T: The Halifax interlaminar clamp for posterior cervical fusion: initial experience in the United Kingdom. Neurosurgery 32:396-399, 1993

76. Steinhausen TB, Dungan CE, Furst JB, et al: Iodinated organic compounds as contrast media for radiographic diagnoses. III. Experimental and clinical myelography with ethyl iodophenylundecylate (Pantopaque). Radiology 43:230-234, 1944 


\section{Evolution of posterior cervical and occipitocervical fusion}

77. Takayasu M, Hara M, Yamauchi K, et al: Transarticular screw fixation in the middle and lower cervical spine. Technical note. J Neurosurg (Spine 1) 99:132-136, 2003

78. Tucker HH: Technical report: method of fixation of subluxed or dislocated cervical spine below C1-C2. Can J Neurol Sci 2: 381-382, 1975

79. Vale FL, Oliver M, Cahill DW: Rigid occipitocervical fusion. J Neurosurg (Spine 2) 91:144-150, 1999

80. Vender JR Houle PJ, Harrison S, et al: Occipital-cervical fusion using the Locksley intersegmental tie bar technique: long-term experience with 19 patients. Spine J 2:134-141, 2002

81. Wang MY, Prusmack CJ, Green BA, et al: Minimally invasive lateral mass screws in the treatment of cervical facet dislocations: technical note. Neurosurgery 52:444-448, 2003
82. Watts C, Smith H, Knoller N: Risks and cost-effectiveness of sublaminar wiring and posterior fusion of cervical spine trauma. Surg Neurol 40:457-460, 1993

83. Weis JC, Cunningham BW, Kanayama M, et al: In vitro biomechanical comparison of multistrand cables with conventional cervical stabilization. Spine 21:2108-2114, 1996

Manuscript received November 20, 2003.

Accepted in final form December 11, 2003.

Address reprint requests to: John R. Vender, M.D., Department of Neurosurgery, BI3088, Medical College of Georgia, 1120 15th Street, Augusta, Georgia 30912. email: jvender@mail.mcg.edu. 